\title{
INCORPORAÇÃO DE MICRORGANISMOS, AMINOÁCIDOS, MICRONUTRIENTES E REGULADORES DE CRESCIMENTO EM SEMENTES DE ALFACE PELA TÉCNICADE PELICULIZAÇÃ̃O ${ }^{1}$
}

\author{
KÊNIAALMEIDADINIZ², JOÃOALMIR OLIVEIRA ${ }^{3}$, RENATO MENDES GUIMARÃES ${ }^{3}$, \\ MARIALAENE MOREIRADE CARVALHO ${ }^{3}$, JOSÉ DACRUZMACHADO ${ }^{3}$
}

\begin{abstract}
RESUMO - A peliculização é uma tecnologia que permite, dentre outros usos, a inoculação de microrganismos e a incorporação de aditivos às sementes, sem mudança no seu tamanho ou forma e é uma estratégia para garantir alto potencial de emergência em campo, ganhos de produtividade e melhor agregação de insumos agrícolas às sementes. O experimento foi conduzido na Universidade Federal de Lavras, com o objetivo de avaliar o efeito da incorporação de alguns microrganismos antagônicos, micorrizas, aminoácidos, micronutrientes e reguladores de crescimento, pela técnica de peliculização, na qualidade de sementes e mudas de alface. As sementes foram revestidas com dois tipos de polímeros, adicionando-se microrganismos antagônicos (Trichoderma viride, Trichoderma polysporhum, Trichoderma stromaticum, Beauveria bassiana, Metarhizium anisopliae), micorrizas, aminoácidos, micronutrientes e reguladores de crescimento com a metodologia e as dosagens recomendadas pelo fabricante dos produtos. Avaliou-se as porcentagens de germinação e emergência, o índice de velocidade de emergência, o número de plantas, a massa seca da parte aérea e da raiz e a altura de parte aérea das mudas. Concluiu-se a microbiolização de sementes com a mistura dos microrganismos Trichoderma viride, T. polysporhum, T. stromaticum, Beauveria bassiana, Metarhizium anisopliae e micorrizas reduz a germinação das sementes de alface. A inoculação de sementes de alface com Trichoderma viride e com reguladores de crescimento promovem aumento na emergência e no índice de veolicadade de emergência das plântulas.
\end{abstract}

Termos para indexação: Lactuca sativa, revestimento, microbiolização.

\section{INCORPORATION OF MICROORGANISM,AMINO ACIDS, MICRONUTRIENTS AND GROWTH REGULATORS IN LETTUCE SEED THROUGH THE COATING TECHNIQUE}

\begin{abstract}
Seed coating is a technology that allows incorporation of additive to the seeds, without change its size or form. The coating technique is a strategy that guarantees high seedling emergence in the field, gain in productivity and better aggregation of agricultural inputs to the seeds. Thus, this study had the objective of evaluating the effect of the incorporation of antagonistic microorganisms, mycorrhiza, amino acids, micronutrients and growth regulators through the seed coating technique on the quality of lettuce seeds. The seeds were coated with two types of polymer that were applied together with antagonistic microorganisms (Trichoderma viride, Trichoderma polysporhum, Trichoderma stromaticum, Beauveria bassiana, Metarhizium anisopliae), mycorrhiza, amino acids, micronutrients and growth regulators according to the methodology proposed by the manufacturer. The germination percentage and emergence, the emergence speed index, the number of plants, the dry mass of aerial and root parts and the height of the seedlings were evaluated. Microbiolization of the seeds with the mixture of microorganisms
\end{abstract}

\footnotetext{
${ }^{1}$ Submetido em 22/02/2005. Aceito para a publicação em 26/06/2006. Parte da dissertação de mestrado do primeiro autor apresentada à Universidade Federal de Lavras;

${ }^{2}$ Doutoranda da Universidade Federal de Lavras, Caixa Postal 37, CEP:
}

37200-000, Lavras - MG, keniadiniz@hotmail.com;

${ }^{3}$ Professor, Dr., Universidade Federal de Lavras, Caixa Postal 37, CEP: 37200-000, Lavras - MG, jalmir@ufla.br. 
Trichoderma viride, T. polysporhum, T. stromaticum, Beauveria bassiana, Metarhizium anisopliae and mycorrhiza negatively affected the quality of the lettuce seeds. The inoculation of lettuce seeds with Trichoderma viride and growth regulator increased the percentage and the seedling emergence speed index.

Index terms: Lactuca sativa, coating, microbiolization.

\section{INTRODUÇÃO}

A agricultura orgânica vem se tornando opção importante, atendendo uma crescente demanda dos consumidores, tanto em nível nacional quanto internacional, cujas exigências criam nichos de mercado que são cada vez mais exigentes em relação à qualidade e segurança de produtos alimentares.

Neste contexto, o tratamento de sementes com alguns microrganismos tem sido utilizado, pois, além de proteger as plantas contra fitopatógenos, pode promover o seu crescimento. Esse mecanismo se refere ao desenvolvimento das plantas de forma geral, incluindo os efeitos benéficos na germinação de sementes, emergência e desenvolvimento das plântulas e produção de grãos e frutos (Harman, 2000).

No cultivo de grande número de espécies olerícolas, além da utilização de microrganismos antagônicos, a incorporação de aminoácidos, micronutrientes, reguladores de crescimento e micorrizas, tem sido pesquisada, visando produtos menos agressivos ao ambiente, melhor desenvolvimento das mudas para obtenção de maiores produtividades e melhor agregação de insumos agrícolas às sementes.

A peliculização é uma tecnologia que permite, dentre outros usos, a adição de insumos agrícolas às sementes, sem mudança no seu tamanho ou forma, juntamente com o tratamento químico, já é utilizada para algumas sementes de espécies olerícolas. A resposta a esses materiais de recobrimento depende muito das características de cada espécie, como também dos materiais utilizados para a peliculização (Trentini, 2004).

Desta forma, o presente trabalho teve como objetivo avaliar o efeito da incorporação de alguns microrganismos antagônicos, micorrizas, aminoácidos, micronutrientes e reguladores de crescimento, pela técnica de peliculização, na qualidade de sementes e de mudas de alface.

\section{MATERIAL E MÉTODOS}

O experimento foi conduzido no Laboratório de Análise de Sementes, na casa de vegetação do Departamento de
Agricultura e no Laboratório de Patologia de Sementes do Departamento de Fitopatologia da Universidade Federal de Lavras, Minas Gerais.

As sementes de alface foram revestidas com dois tipos de polímeros, adicionando-se microrganismos antagônicos (Trichoderma viride, Trichoderma polysporhum, Trichoderma stromaticum, Beauveria bassiana e Metarhizium), micorrizas, aminoácidos, micronutrientes e reguladores de crescimento, divididos em dois ensaios distintos. Para cada $100 \mathrm{~g}$ dos inóculos, acrescentou-se um quilo de talco para facilitar a aplicação e homogeneização do produto nas sementes.

Para a peliculização das sementes, os polímeros foram primeiramente diluídos em água, em iguais proporções, ou seja, $50 \mathrm{~mL}$ do polímero para $50 \mathrm{~mL}$ de água. As sementes foram então revestidas com essa mistura na dose de $50 \mathrm{~mL} . \mathrm{kg}$ ${ }^{1}$ de sementes. Todos os produtos utilizados no experimento foram cedidos pela INCOTEC. O teste de viabilidade dos inóculos foi realizado pelas empresas fornecedoras dos produtos.

Ensaio I - Peliculização e inoculação de microrganismos

As sementes foram peliculizadas com o polímero Disco Trichodermina ${ }^{\circledR}$ e inoculadas com os microrganismos antagônicos nas dosagens de $100 \mathrm{~g} .100 \mathrm{~kg}^{-1}$ de sementes. Para a inoculação das sementes com micorrizas, utilizou-se a dosagem de $500 \mathrm{~g} .100 \mathrm{~kg}^{-1}$ de sementes. A mistura e a metodologia de aplicação foram adotadas de acordo com as recomendações dos próprios fabricantes, compondo os seguintes tratamentos:

1. sementes sem revestimento (testemunha);

2. sementes com Disco Trichodermina ${ }^{\circledR}$;

3. sementes com Disco Trichodermina ${ }^{\circledR}+$ Trichoderma viride;

4. sementes com Disco Trichodermina ${ }^{\circledR}+T$. viride/T. polysporhum/T. stromaticum;

5. sementes com Disco Trichodermina ${ }^{\circledR}+$ Metarhizium anisopliae;

6. sementes com Disco Trichodermina ${ }^{\circledR}+$ Beauveria bassiana;

7. sementes com Disco Trichodermina ${ }^{\circledR}+$ micorrizas;

8. sementes com Disco Trichodermina ${ }^{\circledR}+T$. viride $/ T$. 
polysporhum/T. stromaticum + Metarhizium anisopliae + Beauveria bassiana + micorrizas.

Ensaio II - Peliculização e aplicação de aminoácidos, micronutrientes, regulador de crescimento e Trichoderma viride

As sementes revestidas com aminoácidos, micronutrientes e regulador de crescimento foram previamente recobertas com o polímero Disco Clear ${ }^{\circledR}$ e as sementes inoculadas com Trichoderma viride foram previamente peliculizadas com o polímero Disco trichodermina ${ }^{\circledR}$. O ensaio foi composto dos seguintes tratamentos:

1. sementes sem revestimento (testemunha);

2. sementes com Disco Clear ${ }^{\circledR}+$ micronutrientes (200g. $\left.100 \mathrm{~kg}^{-1}\right)$;

3. sementes com Disco Clear ${ }^{\circledR}+$ micronutrientes (400g. $\left.100 \mathrm{~kg}^{-1}\right)$;

4. sementes com Disco Clear ${ }^{\circledR}+$ regulador de crescimento $\left(5 \mathrm{~mL} \cdot \mathrm{kg}^{-1}\right)$;

5. sementes com Disco Clear ${ }^{\circledR}+$ regulador de crescimento $\left(10 \mathrm{~mL} \cdot \mathrm{kg}^{-1}\right)$;

6. sementes com Disco Clear ${ }^{\circledR}+$ aminoácidos $+\mathrm{Zn}$ $\left(5 \mathrm{~mL} \cdot \mathrm{kg}^{-1}\right)$;

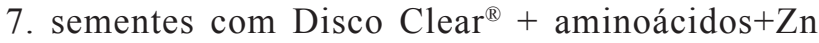
$\left(10 \mathrm{~mL} \cdot \mathrm{kg}^{-1}\right)$;

8. sementes com Disco Trichodermina ${ }^{\circledR}+$ Trichoderma viride $\left(200 \mathrm{~g} .100 \mathrm{~kg}^{-1}\right)$.

Os produtos utilizados na composição dos tratamentos foram cedidos pela empresa Incotec, com os nomes comerciais Bruxil ${ }^{\circledR}$ (micronutrientes), Aminoácidos $+\mathrm{Zn}^{\circledR} \mathrm{e}$ Stimulate ${ }^{\mathbb{B}}$ (regulador de crescimento - giberelinas, citocininas e auxinas).

Por se tratarem de volumes pequenos de sementes, todos os produtos foram aplicados manualmente, em sacos plásticos de composição química neutra (Machado, 2000), com agitação até a completa distribuição do produto nas sementes (Ruano et al., 1989).

Após o tratamento das sementes com cada produto, foram realizados, nos dois ensaios, os testes, descritos a seguir.

Teste de germinação: a semeadura foi realizada em caixas plásticas (gerbox) sobre papel mata-borrão umedecido com água destilada, em quantidade equivalente a 2,5 vezes o peso do substrato seco. A seguir, as caixas de gerbox foram transferidas para câmara de germinação (BOD), em regime alternado de luz e escuro (12 horas), regulado à temperatura de $20^{\circ} \mathrm{C}$. Foram utilizadas 4 repetições de 100 sementes por tratamento e os resultados foram expressos em porcentagem de plântulas normais, segundo as Regras para Análise de Sementes - RAS (Brasil, 1992).

Teste de emergência em condições controladas: a semeadura foi realizada em substrato solo + areia na proporção 1:2 em bandejas plásticas. A umidade do substrato foi ajustada para $60 \%$ da capacidade de retenção. Foram utilizadas 4 repetições de 100 sementes por tratamento. Após a semeadura, as bandejas foram mantidas em câmara de crescimento vegetal, previamente regulada à temperatura $20^{\circ} \mathrm{C}$, em regime alternado de luz e escuro (12 horas). A partir do início da emergência foram realizadas avaliações diárias, computandose o número de plântulas emergidas até a estabilização. Considerou-se a porcentagem de emergência e o índice de velocidade de emergência, determinado segundo fórmula proposta por Maguire (1962).

Obtenção das mudas: a semeadura foi realizada em substrato comercial PLANTMAX ${ }^{\circledR}$ em bandeja de isopor de 128 células. Foram utilizadas 4 repetições de 100 sementes por tratamento. No primeiro ensaio as bandejas foram mantidas em um galpão coberto, com temperatura ambiente e irrigação duas vezes ao dia. No segundo ensaio, o teste foi realizado em casa de vegetação, com temperatura controlada e sistema de irrigação automatizado. Quando as mudas atingiram o ponto de transplantio (30 dias), fez-se a contagem das mesmas e mediu-se sua altura de parte aérea com auxílio de régua graduada. Depois as mudas foram retiradas do substrato, lavadas em água corrente, separando-se o sistema radicular da parte aérea, acondicionadas separadamente em sacos de papel e levadas à estufa com circulação forçada de ar, regulada à temperatura de $60^{\circ} \mathrm{C}$, até o material atingir peso constante. Desta forma, foram calculadas as massas secas de raiz e parte aérea, sendo os resultados expressos em gramas por planta.

Teste de sanidade: foram analisadas 200 sementes, distribuídas em 4 repetições de 50 sementes, semeadas em placa de Petri, sobre duas folhas de papel de filtro umedecidas com água destilada e autoclavada, conforme metodologia proposta por Machado (2000). Após a semeadura, as placas foram colocadas em câmara de crescimento à temperatura de $22^{\circ} \mathrm{C}$ por sete dias, quando foi avaliado o crescimento do fungo inoculado bem como a presença dos demais microrganismos existentes.

Os ensaios foram conduzidos seguindo o delineamento inteiramente casualizado, com quatro repetições e 8 tratamentos, num total de 32 parcelas.

Os dados foram previamente submetidos aos testes de normalidade dos resíduos e homocedasticidade das variâncias. 
As análises estatísticas foram realizadas com o auxílio do programa SANEST (Zonta e Machado, 1984) e os dados foram submetidos à análise de variância. As médias entre os tratamentos foram comparadas pelo teste de Tukey a 5\% de probabilidade e os dados referentes às dosagens dos produtos foram avaliados pela análise de regressão polinomial.

\section{RESULTADOS E DISCUSSÃO}

Ensaio I - Peliculização e inoculação de microrganismos

Nos resultados da inoculação de sementes de alface com microrganismos, verificou-se diferença significativa pelo teste de $\mathrm{F}$ apenas para germinação e altura de mudas. Houve tendência das sementes inoculadas com Beauveria bassiana apresentarem maior porcentagem de germinação quando comparadas à testemunha (Tabela 1), embora tenha diferido apenas das sementes que foram inoculadas com a mistura de todos os microrganismos.

As sementes revestidas apenas com o Disco Trichodermina ${ }^{\circledR}$ originaram mudas mais altas em condições de campo (Tabela 1), diferindo estatisticamente da testemunha e daquelas que foram inoculadas com espécies do gênero Trichoderma e com Metarhizium anisopliae. Os efeitos benéficos da inoculação de sementes com Trichoderma sp. podem ter sido limitados pelas condições ideais de temperatura e umidade por ocasião da semeadura. Harman (2000) relata que a promoção de crescimento pelo Trichoderma sp. depende da concentração, idade do inóculo e vigor das sementes que, em ótimas condições fisiológicas e edáficas, proporciona pouco ou nenhum efeito benéfico.

Observou-se uma baixa incidência de fungos patogênicos no teste de sanidade das sementes de alface em todos os tratamentos avaliados (Tabela 2). No tratamento com inoculação de Trichoderma viride verificou-se que $70 \%$ das sementes estavam contaminadas com o fungo. Os demais microrganismos que foram inoculados não se desenvolveram nas condições do teste de sanidade, provavelmente pelo fato dos mesmos requererem meios específicos.

Ensaio II - Peliculização e incorporação de aminoácidos, micronutrientes, regulador de crescimento e Trichoderma viride

As características porcentagem de emergência, índice de velocidade de emergência e massa seca de parte aérea apresentaram diferença significativa pelo teste de F. De forma geral, as sementes inoculadas com Trichoderma viride apresentaram maior desempenho nas três características (Tabela 3), não diferindo do tratamento controle apenas para a característica massa seca de parte aérea.

As maiores porcentagens de emergência foram obtidas para as sementes inoculadas com Trichoderma viride e revestidas com o regulador de crescimento nas duas dosagens, diferindo apenas do tratamento controle. Com relação ao índice de velocidade de emergência, as sementes de alface inoculadas com Trichoderma viride apresentaram resultados superiores a todos os tratamentos (Tabela 3). Estes resultados estão de acordo com os encontrados por Windhan et al. (1986), os quais, trabalhando com sementes de tomate e fumo em solos autoclavados e inoculadas com Trichoderma, observaram aumento na emergência das plântulas. Já Resende (2003), encontrou redução no índice de velocidade de emergência quando inoculou Trichoderma harzianum em sementes de milho.

Os tratamentos com o regulador de crescimento, independente da dosagem também foram superiores à

TABELA 1. Germinação e altura de parte aérea das mudas oriundas de sementes de alface revestidas com diferentes materiais (Ensaio I). UFLA, Lavras, MG, 2005.

\begin{tabular}{lcc}
\hline Tratamentos & Germinação (\%) & Altura $(\mathrm{cm})$ \\
\hline Testemunha & $94,44 \mathrm{ab}$ & $9,99 \mathrm{bc}$ \\
Disco Trichodermina ${ }^{\circledR}$ & $96,68 \mathrm{ab}$ & $12,55 \mathrm{a}$ \\
Trichoderma viride & $91,13 \mathrm{ab}$ & $10,22 \mathrm{bc}$ \\
Mistura Trichoderma sp. & $94,53 \mathrm{ab}$ & $9,76 \mathrm{bc}$ \\
Metarhizium anisopliae & $94,36 \mathrm{ab}$ & $9,56 \mathrm{c}$ \\
Beauveria bassiana & $98,47 \mathrm{a}$ & $11,82 \mathrm{abc}$ \\
Micorriza & $94,08 \mathrm{ab}$ & $11,39 \mathrm{abc}$ \\
Mistura dos trat.4, 5, 6 e 7 & $86,07 \mathrm{~b}$ & $12,07 \mathrm{ab}$ \\
\hline
\end{tabular}

Médias seguidas por letras distintas, na coluna, diferem entre si pelo teste de Tukey a $5 \%$ de probabilidade.

4. sementes com Disco Trichodermina ${ }^{\circledR}+T$. viride/T. polysporhum $/ T$. stromaticum; 5. sementes com Disco Trichodermina ${ }^{\circledR}+$ Metarhizium anisopliae; 6 . sementes com Disco Trichodermina ${ }^{\circledR}+$ Beauveria bassiana; 7. sementes com Disco Trichodermina ${ }^{\circledR}+$ micorrizas

TABELA 2. Incidência de fungos em (\%) em sementes de alface revestidas com diferentes materiais (Ensaio I). UFLA, Lavras, MG, 2005.

\begin{tabular}{lcccccccc}
\hline \multirow{2}{*}{ Patógenos } & \multicolumn{8}{c}{ Tratamentos } \\
\cline { 2 - 9 } & 1 & 2 & 3 & 4 & 5 & 6 & 7 & 8 \\
\hline Aspergillus sp. & 0,5 & 0,0 & 0,0 & 0,5 & 0,0 & 0,0 & 0,0 & 0,0 \\
Trichoderma $\mathrm{sp}$. & 0,0 & 0,0 & 70,0 & 0,0 & 0,0 & 0,0 & 0,0 & 0,0 \\
Alternaria sp. & 0,0 & 0,0 & 0,0 & 0,0 & 0,5 & 0,0 & 0,5 & 0,0 \\
Fusarium $\mathrm{sp}$. & 0,0 & 0,0 & 0,0 & 0,0 & 0,0 & 0,0 & 0,0 & 0,5 \\
\hline
\end{tabular}

1 - Testemunha; 2 - Disco Trichodermina; 3 - Trichoderma viride; $4-T$ viride $+T$. polysporhum $+T$. stromaticum $; 5$-Metarhizium anisopliae; $6-$ Beauveria bassiana; 7 - Micorriza; 8 - Mistura dos tratamentos 4, 5, 6 e7. 
TABELA 3. Emergência (E), índice de velocidade de emergência (IVE) e massa seca de parte aérea (MSPA) de mudas oriundas de sementes de alface revestidas com diferentes materiais (Ensaio II). UFLA, Lavras, MG, 2005.

\begin{tabular}{lccc}
\hline TRATAMENTOS & \multicolumn{3}{c}{ Características Avaliadas } \\
\hline & $\mathrm{E}(\%)$ & $\mathrm{IVE}$ & $\mathrm{MSPA}(\mathrm{g})$ \\
\cline { 2 - 3 } Testemunha & $84,94 \mathrm{~b}$ & $12,58 \mathrm{~d}$ & $0,102 \mathrm{ab}$ \\
Micronutrientes $(200 \mathrm{~g})$ & $92,58 \mathrm{ab}$ & $14,88 \mathrm{~cd}$ & $0,088 \mathrm{ab}$ \\
Micronutrientes $(400 \mathrm{~g})$ & $94,84 \mathrm{ab}$ & $15,15 \mathrm{~cd}$ & $0,096 \mathrm{ab}$ \\
Regulador de crescimento $(5 \mathrm{~mL})$ & $98,54 \mathrm{a}$ & $18,15 \mathrm{~b}$ & $0,084 \mathrm{~b}$ \\
Regulador de crescimento $(10 \mathrm{~mL})$ & $99,08 \mathrm{a}$ & $15,98 \mathrm{bc}$ & $0,087 \mathrm{ab}$ \\
Aminoácidos + Zn $(5 \%)$ & $88,38 \mathrm{ab}$ & $13,50 \mathrm{~cd}$ & $0,095 \mathrm{ab}$ \\
Aminoácidos $+\mathrm{Zn}(10 \%)$ & $93,67 \mathrm{ab}$ & $13,79 \mathrm{~cd}$ & $0,083 \mathrm{~b}$ \\
Trichoderma viride & $99,26 \mathrm{a}$ & $24,32 \mathrm{a}$ & $0,112 \mathrm{a}$ \\
\hline
\end{tabular}

Médias seguidas por letras distintas, na coluna, diferem entre si pelo teste de Tukey a 5\% de probabilidade.

testemunha quanto ao índice de velocidade de emergência das sementes de alface (Tabela 3).

A inoculação das sementes com Trichoderma viride proporcionou os maiores resultados em relação à massa seca da parte aérea das mudas, porém, diferindo apenas do tratamento com o regulador de crescimento $(5 \mathrm{~mL})$ e do tratamento com aminoácidos $+\mathrm{Zn}(10 \mathrm{~mL})$, que não diferiram dos demais (Tabela 3).

Pela análise de regressão polinomial, referente à emergência das plântulas, observa-se que houve



comportamento linear tanto para o tratamento com o regulador de crescimento quanto para o tratamento com micronutrientes. Assim, quanto maior a dose, maior a porcentagem de emergência (Figura 1).

Para o índice de velocidade de emergência (IVE), houve comportamento distinto entre os dois tratamentos. Verificouse que o índice foi superior para as sementes tratadas até a dose de $5 \mathrm{~mL} . \mathrm{kg}^{-1}$ de sementes do regulador de crescimento, decrescendo a partir desse ponto (Figura 2). Já para o tratamento com micronutrientes observou-se comportamento

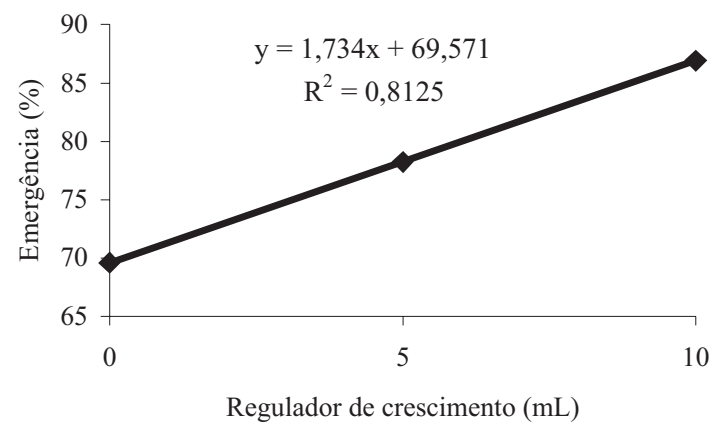

FIGURA 1. Emergência de sementes de alface tratadas com diferentes doses de micronutrientes e regulador de crescimento (Ensaio II). UFLA, Lavras, MG, 2005.
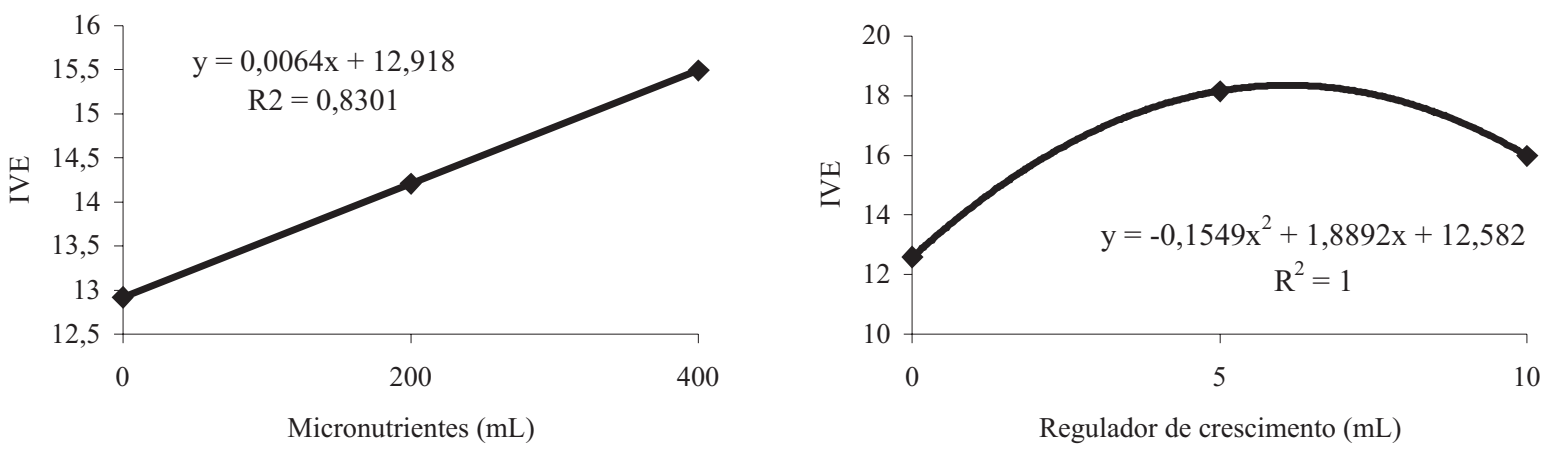

FIGURA 2. Índice de velocidade de emergência (IVE) de sementes de alface tratadas com diferentes doses de micronutrientes e regulador de crescimento (Ensaio II). UFLA, Lavras, MG, 2005. 
linear, ou seja, à medida que a dose foi aumentada, houve acréscimo no índice.

Trabalhando com revestimento de sementes de milheto com micronutrientes, Cabezas (2004) constatou aumento na germinação e na massa seca das plantas com a incorporação deste aditivo.

Porém, no tratamento com o regulador de crescimento também se observou que com o uso do produto ocorreu pequeno decréscimo na massa seca de parte aérea das mudas, como pode ser observado na Figura 3.

A maior incidência de Aspergillus sp no tratamento com sementes sem revestimento (Tabela 4), pode ter afetado seu desempenho, o que não ocorreu nos demais tratamentos, já que polímeros aderidos às sementes podem protegê-la contra

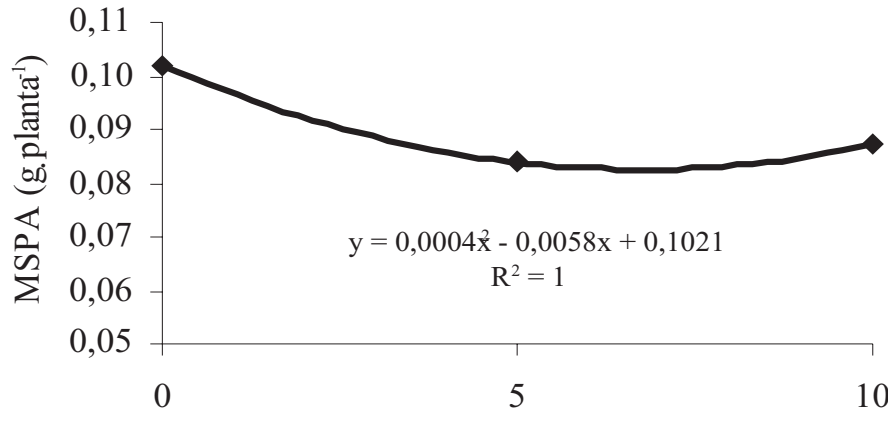

Regulador de crescimento $(\mathrm{mL})$

FIGURA 3. Massa seca de parte aérea (MSPA) de mudas de alface oriundas de sementes tratadas com de diferentes doses de regulador de crescimento (Ensaio II). UFLA, Lavras, MG, 2005.

TABELA 4. Incidência de fungos (\%) em sementes de alface revestidas com diferentes materiais (Ensaio II). UFLA, Lavras, MG, 2005.

\begin{tabular}{lcccccccc}
\hline \multirow{2}{*}{ PÁTÓGGENos } & \multicolumn{1}{c}{ TRATAMENTOS } \\
\cline { 2 - 9 } & 1 & 2 & 3 & 4 & 5 & 6 & 7 & 8 \\
\hline Aspergillus sp. & 6,0 & 1,0 & 0,0 & 0,0 & 0,0 & 0,0 & 0,0 & 0,0 \\
Phoma sp. & 3,0 & 0,0 & 0,0 & 0,0 & 0,0 & 1,0 & 0,0 & 0,0 \\
Alternaria sp. & 3,0 & 6,0 & 6,0 & 2,0 & 1,0 & 6,0 & 7,0 & 2,0 \\
Cladisporium sp. & 1,0 & 0,0 & 0,0 & 0,0 & 0,0 & 0,0 & 0,0 & 0,0 \\
Fusarium sp & 0,0 & 1,0 & 0,0 & 0,0 & 1,0 & 0,0 & 1,0 & 1,0 \\
Curvularia sp. & 0,0 & 0,0 & 0,0 & 0,0 & 0,0 & 1,0 & 1,0 & 1,0 \\
Trichoderma sp. & 0,0 & 0,0 & 0,0 & 0,0 & 0,0 & 0,0 & 0,0 & 65,5 \\
\hline
\end{tabular}

1 - Testemunha; 2 - Micronutrientes (200mL); 3 - Micronutrientes (400mL); 4 - Regulador de crescimento (5mL); 5 - Regulador de crescimento (10mL); 6 - Aminoácidos $+\mathrm{Zn}(5 \mathrm{~mL}) ; 7$ - Aminoácidos $+\mathrm{Zn}(10 \mathrm{~mL}) ; 8$ - Trichoderma viride.

ataque de patógenos. Porém, nos tratamentos com micronutrientes e aminoácidos $+\mathrm{Zn}$, houve pequeno aumento na incidência de Alternaria sp., o que provavelmente promoveu efeito estimulante do fungo encontrado nas sementes revestidas com esses insumos. Pode-se verificar que $65 \%$ das sementes estavam contaminadas com o fungo Trichoderma viride, que foi inoculado nas sementes.

\section{CONCLUSÕES}

A microbiolização de sementes com a mistura dos microrganismos Trichoderma viride, T. polysporhum, T. stromaticum, Beauveria bassiana, Metarhizium anisopliae e micorrizas reduz a germinação das sementes de alface.

A inoculação de sementes de alface com Trichoderma viride e com reguladores de crescimento promovem aumento na emergência e no índice de velocidade de emergência das plântulas.

\section{REFERÊNCIAS}

BRASIL. Ministério da Agricultura e Reforma Agrária. Regras para análise de sementes. Brasília: SNDA/DNDV/CLAV, 1992. $365 \mathrm{p}$.

CABEZAS, W. A. R. L. Sobressemeadura com sementes de milheto revestidas no Triângulo Mineiro-MG: estudo preliminar. Revista Plantio Direto, Passo Fundo, RS, v. 79, p. 16-18, 2004.

HARMAN, G.E. Myth and dogmas of biocontrol changes in perceptions derived from research on Trichoderma harzianum T22. Plant Diasease, St. Paul, v.84, p.377-393, 2000.

MACHADO, J.C. Tratamento de sementes no controle de doenças. Lavras: LAPS/UFLA/FAEPE, 2000. 138 p.

MAGUIRE, J.D. Speed of germination-aid selection and evaluation for seedling emergence and vigor. Crop Science, Madison, v.2, n,2, p.176-177, 1962 .

RESENDE, M.L. Inoculação de sementes com Trichoderma harzianum, tratamento fungicida e adubação nitrogenada na cultura do milho. 2003. 95 f. Dissertação (Mestrado em Fitotecnia)Universidade Federal de Lavras, Lavras, 2003. 
RUANO, O.; PIRES, J.R.; ALMEIDA, W. P.; YAMAOKA, R.S.; COSTA, A.; MARUR, C.J.; TURKIEWICZ, L.; SANTOS, W. J. Prevenção do tombamento do algodoeiro através do tratamento de sementes com fungicidas. Londrina: IAPAR, 1989. 6p. (Informe de Pesquisa, v.13, n.88).

TRENTINI, P. Peliculização: preservação da qualidade de sementes de soja e desempenho no estabelecimento da cultura em campo na região de Alto Garças, MT. 2004. 117 f. Dissertação
(Mestrado em Fitotecnia) - Universidade Federal de Lavras, Lavras, 2004.

WINDHAN, M.T.; ELAD, Y.; BACKER, R. A mechanism for increases plant growth induced by Trichoderma sp.. Phytopathology, St. Paul, v.76, n.6, p.518-521, 1986.

ZONTA, E.P.; MACHADO, A.A. Sistema de análise estatística para microcomputadores - Sanest. Pelotas: UFPel, 1984. 109p.

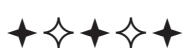

